\title{
Observations on the Regulation of Uricase Activity During Development of Drosophila melanogaster
}

\author{
Thomas B. Friedman ${ }^{1,2}$
}

Received 27 Sept. 1971-Final 8 May 1972

To elucidate the mechanisms involved in the regulation of uricase activity in Drosophila melanogaster, a comparative analysis of the patterns of uricase activity during development was undertaken for the wild type, Ore- $\mathrm{R}$, and the mutants $\mathrm{ry}^{2}$ and ma-1. Uricase activity in $\mathrm{ry}^{2}$ and ma-1, unlike that in Ore-R, increased rapidly following emergence of the adult. This study indicates that uricase in Drosophila, in contrast to that in several microorganisms, is not induced by uric acid, since ry ${ }^{2}$ and ma-1 with no detectable uric acid have higher activity than the wild type.

\section{INTRODUCTION}

The regulation of uricase activity has been studied in higher organisms and microorganisms. In higher organisms, the mechanisms responsible for changes in uricase activity during development remain obscure (Barrett, 1964; Brown, 1938; Nelson, 1964). In microorganisms, uricase appears to be induced by uric acid (Scazzocchio and Darlington, 1968; Watanabe and Fukumoto, 1970).

In the present study, the wild-type pattern of uricase activity in the pupa and adult of Drosophila melanogaster was compared with the patterns of uricase activity in the mutants $r y^{2}$ and $m a-l$. These comparisons were undertaken as the initial step to elucidate the mechanisms involved in the regulation

This study was supported by grants from NIH, PHS 5-TO 1 GM 0071-13 and 1F02 HD $50,527-01$

${ }^{1}$ Department of Zoology, University of Michigan, Ann Arbor, Michigan.

${ }^{2}$ Present address: Laboratory of General and Comparative Biochemistry, National Institute of Health, Bethesda, Maryland.

(C) 1973 Plenum Publishing Corporation, 227 West 17th Street, New York, N.Y. 10011. 
of uricase activity in Drosophila. For this purpose, the mutants $r y^{2}$ and ma-l were of particular interest, since both lack detectable levels of uric acid due to the absence of xanthine dehydrogenase (Glassman and Mitchell, 1959a; Morita, 1958; Glassman, 1965).

\section{MATERIALS AND METHODS}

\section{Genetic Stocks}

From electrophoretic studies, the rosy locus (ry: 3-52) appears to be the structural gene for xanthine dehydrogenase (Yen and Glassman, 1965). The biochemical basis for the absence of xanthine dehydrogenase, pyridoxal oxidase, and aldehyde oxidase in maroon-like (ma-l: 1-64.8) remains unexplained (Glassman, 1965; Glassman et al., 1968; Collins and Glassman, 1969; Courtright, 1967). Stocks of Drosophila were provided by Dr. T. M. Rizki and Dr. I Oster.

\section{Media}

Adult and larval Drosophila were raised at $25 \mathrm{C}$ on standard cornmealmolasses-yeast food and cream of wheat food, respectively.

\section{Enzyme Preparation}

Homogenates were prepared by grinding whole flies or individual tissues from adults in ice-cold $0.25 \mathrm{M}$ sucrose, $p \mathrm{H} \mathrm{7.5.} \mathrm{Either} 20$ xanthine dehydrogenase-deficient or 50 wild-type individuals were homogenized, filtered through cheesecloth to remove chitin, and adjusted to a final volume of 2.0 $\mathrm{ml}$. The protein concentrations were approximately $1.2 \mathrm{mg} / \mathrm{ml}$ and 2.7 $\mathrm{mg} / \mathrm{ml}$, respectively, for 1-day-old adults (Lowry et al., 1951).

\section{Determination of Uricase Activity}

Uricase (E.C. 1.7.3.3) was assayed by the spectrophotometric method described by Kalckar (1947) and Praetorius (1948) and modified by Tuskuda et al. (1968). To each sample were added the following reagents: $0.2 \mathrm{ml}$ of

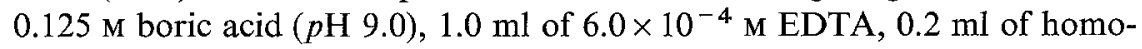
genate, and $0.2 \mathrm{ml}$ of $5.26 \times 10^{-4} \mathrm{M}$ sodium urate. Control experiments omitted either sodium urate or homogenate until the end of the $90 \mathrm{~min}$ incubation period. After incubation, the reaction was stopped with $1.0 \mathrm{ml}$ of ice-cold $10 \%$ trichloroacetic acid. Samples were then centrifuged for 20 $\min$ at $1470 \times g$. The difference in optical density at $292 \mathrm{~nm}$ between control and experimental indicated the level of uricase activity, since allantoin, the reaction product, does not absorb light at $292 \mathrm{~nm}$. 
Uricase activity was found to be linear with respect to time and concentration of protein for $210 \mathrm{~min}$ or until a change in optical density exceeded 0.30 . The specific activity of uricase was defined as the change in optical density at $292 \mathrm{~nm}$ in $90 \mathrm{~min}$ per individual. The kinetics of uricase activity were measured for $O r e-R, r y^{2}$, and $m a-l . K_{m}$ values were calculated by the method of Lineweaver and Burke.

\section{Determination of Catalase Activity}

Catalase (E.C. 1.11.1.6) was assayed according to the method of Baudhuin et al. (1964).

\section{RESULTS}

\section{Kinetics of Uricase}

Enzyme preparations from all genotypes had a single $p \mathrm{H}$ optimum of 9.0 and a temperature optimum at $26 \mathrm{C}$. The EDTA concentration and ionic strength of the buffer gave maximal activity for all strains. All 24-hr-old and 10-dayold Ore-R, ma-l, and $r y^{2}$ adults had $K_{m}$ values within 2 SD of the mean $K_{m}$, $4.35 \times 10^{-5} \mathrm{M}$.

\section{Localization of Uricase}

All the major tissues of males and females were separated and individually assayed. Uricase activity was detected only in the Malpighian tubules, an observation consistent with those made by Razet (1953) and Nelson (1964) for other Diptera.

\section{Effect of Various Metabolites on Uricase Activity}

Uricase activity was measured in the presence of the following metabolites: allantoin, xanthine, hypoxanthine, 2,6,8-trichloropurine, 2-amino-4-hydroxypteridine, and isoxanthopterin. All were inhibitory except allantoin (Table I).

\section{Ontogeny of Uricase}

Uricase activity was detected only in the larva and adult. No uricase activity was found in the puparium using dialyzed or undialyzed homogenates. This pattern of uricase activity is the same as that reported for Musca domestica and Lucilia sericata (Nelson, 1964; Brown, 1938).

Twenty-four hours after emergence, ma-l and $r y^{2}$ males and females had approximately $10-30$ times the activity detected in the wild types, Ore- $R$, 
Table I. Effect of Various Metabolites on Uricase Activity in Vitro

\begin{tabular}{lcc}
\hline \multicolumn{1}{c}{ Reagent in assay } & $\begin{array}{c}\text { Concentration of } \\
\text { reagent in assay } \\
(\mathrm{M})\end{array}$ & $\begin{array}{c}\text { Percent inhibition } \\
\text { of uricase activity }\end{array}$ \\
\hline Allantoin & $6.3 \times 10^{-4}$ & $5.8(4)$ \\
Xanthine & $8.2 \times 10^{-5}$ & $53.5(4)$ \\
Hypoxanthine & $9.2 \times 10^{-5}$ & $9.4(3)$ \\
2, 6, 8-Trichloropurine & $2.8 \times 10^{-5}$ & $67.5(4)$ \\
Isoxanthopterin & $4.2 \times 10^{-5}$ & $41.2(3)$ \\
2-Amino-4-hydroxypteridine & $4.1 \times 10^{-5}$ & $21.2(2)$ \\
\multicolumn{2}{l}{${ }^{a}$ The mean percent inhibition is followed by the number of independent } \\
\multicolumn{2}{l}{ determinations in parentheses. }
\end{tabular}

Swedish-b, and Canton-S (Fig. 1 and Table II). The rapid increase of detectable uricase activity in $m a-l$ and $r y^{2}$ adults was followed by a decline in uricase activity after $1-2$ days.

\section{Mixed Homogenates}

Homogenates of different mutants and sexes were combined and assayed. Mixing experiments indicated that uricase activity was additive regardless of the ratios of protein. Pupal extracts did not inhibit uricase activity from adults.

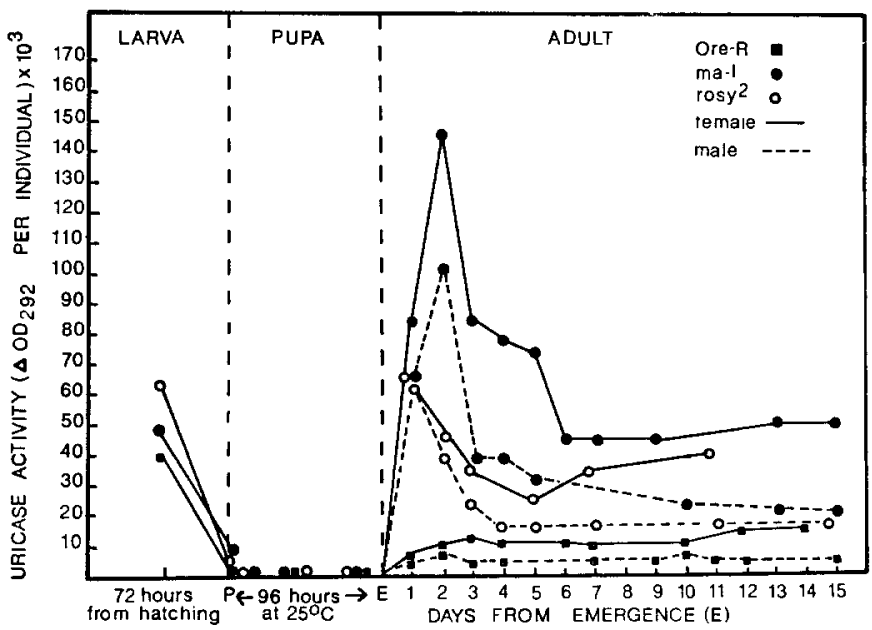

Fig. 1. The pattern of uricase activity in the late third instar larva, pupa, and adult. 
Table II. Comparison of Uricase Activity in 1-Day-Old ma-l and $r y^{2}$ Heterozygotes to that in Homozygotes and Wild Types

\begin{tabular}{|c|c|c|c|c|c|c|}
\hline \multirow{2}{*}{$\begin{array}{c}\mathrm{Age}^{a} \\
\text { (hr) }\end{array}$} & \multicolumn{2}{|c|}{$P_{1}$ genotype } & \multicolumn{2}{|c|}{$F_{1}$ genotype } & \multicolumn{2}{|c|}{ Uricase activity in $F_{1}{ }^{b}$} \\
\hline & Female & Male & Female & Male & Males & Females \\
\hline $23 \pm 3$ & Ore- $R$ & $m a-l$ & $m a-l /+$ & - & - & $20.0 \pm 9.9(2)$ \\
\hline $22 \pm 3$ & $m a-l$ & Ore- $R$ & $m a-l y+$ & - & - & $19.9 \pm 3.8(3)$ \\
\hline $24 \pm 3$ & Ore- $R$ & $r y^{2}$ & $r y^{2} /+$ & $r y^{2} /+$ & $6.5 \pm 0.5(3)$ & $9.3 \pm 4.7(3)$ \\
\hline & Homo & zygotes & & & & \\
\hline $\begin{array}{l}24 \pm 3 \\
24 \pm 3\end{array}$ & $\begin{array}{l}\text { Ore-R } \\
\text { Swedish-b }\end{array}$ & $\begin{array}{l}\text { Ore-R } \\
\text { Swedish } h\end{array}$ & & & $\begin{array}{l}2.4 \pm 0.9(7) \\
4.3+0.6(4)\end{array}$ & $\begin{array}{l}8.5 \pm 2.9(9) \\
5.8+14(3)\end{array}$ \\
\hline $\begin{array}{l}24 \pm 3 \\
24 \pm 3\end{array}$ & $\begin{array}{l}\text { Swedish-b } \\
\text { Canton-S }\end{array}$ & Canton-S & & & $5.3 \pm 1.0(2)$ & $4.9 \pm 0.4(2)$ \\
\hline $24 \pm 3$ & $m a-l$ & $m a-l$ & & & $68.9 \pm 7.4(7)$ & $83.8 \pm 3.7(5)$ \\
\hline $24 \pm 3$ & $r y^{2}$ & $r y^{2}$ & & & $63.1 \pm 8.8(8)$ & $68.8 \pm 11.9(9)$ \\
\hline
\end{tabular}

a Age in hours from emergence of adults from the puparium.

${ }^{b}$ Mean values are followed by standard deviations and the number of independent determinations in parentheses.

\section{Uricase Activity in Starved Flies}

Uricase activity was measured in 24-hr-old adults starved from emergence. There was no significant difference in the amount of uricase activity in ma-l adults with and without food. However, Ore- $R$ females required food for their slow increase in uricase following emergence (Table III).

\section{Uricase Activity in Heterozygotes}

Uricase activity in adults heterozygous for $m a-l$ and $r y^{2}$ was measured to determine whether or not high or low uricase was dominant or recessive.

Table III. Effect of Starving Adults for $24 \mathrm{hr}$ Following Emergence on Uricase Activity

\begin{tabular}{|c|c|c|c|c|c|}
\hline \multirow[b]{2}{*}{ Genotype } & \multirow[b]{2}{*}{$\operatorname{Sex}^{a}$} & \multirow{2}{*}{$\begin{array}{l}\text { Age } \\
\text { (hr) }\end{array}$} & \multicolumn{2}{|c|}{ Uricase activity in flies given: } & \multirow{2}{*}{$\begin{array}{l}\text { Ratio of the } \\
\text { weight of flies } \\
\text { no food/food }\end{array}$} \\
\hline & & & Food $^{b}$ & No food ${ }^{b}$ & \\
\hline Ore $-R$ & $\mathrm{~F}$ & $25 \pm 3$ & $8.7 \pm 2.4(4)$ & $1.8 \pm 0.5(4)$ & $0.74(4)$ \\
\hline Ore- $R$ & $\mathbf{M}$ & $25 \pm 3$ & 2.0 & 2.0 & $0.88(1)$ \\
\hline Ore- $R$ & $M+F$ & $25 \pm 3$ & $6.0 \pm 3.0(5)$ & $1.6 \pm 1.1(5)$ & $0.77(5)$ \\
\hline$m a-l$ & F & $27 \pm 2$ & $94.0 \pm 17.3(3)$ & $92.9 \pm 15.0(3)$ & $0.72(3)$ \\
\hline$m a-l$ & M & $25 \pm 3$ & $66.9 \pm 9.7(3)$ & $69.3 \pm 9.9(3)$ & $0.94(3)$ \\
\hline$m a-l$ & $M+F$ & $27 \pm 2$ & $69.7 \pm 11.1(3)$ & $67.8 \pm 17.6(3)$ & - \\
\hline
\end{tabular}

${ }^{a} \mathrm{M}$, male; $\mathrm{F}$, female.

${ }^{b}$ Mean values are followed by the standard deviations and the number of independent determinations. 
The ma-l heterozygotes have intermediate uricase activity (Table II). The $r y^{2}$ female heterozygotes have uricase activity nearly identical to that of Ore- $R$, while $r y^{2}$ male heterozygotes are only slightly higher. Thus the $r y^{2}$ allele appears to be recessive to the wild type with respect to uricase activity. All singly assayed $r y^{2}$ flies from crosses of $r y^{2}$ heterozygotes had high uricase activity, while the wild type and heterozygotes all had low uricase activity. This eliminates the possibility that high uricase activity is associated with an autosomal recessive other than the $r y$ locus or one closely linked to the $r y$ locus.

\section{Uricase Activity in Maternally Affected ma-l Flies}

Homozygous ma-l females or hemizygous ma-l males which are obtained from heterozygous ma-l females have wild-type eye pigmentation as a result of a maternal effect (Glassman and Mitchell 1959b; Glassman and McLean, 1962). Since maternally affected $m a-l$ adults resemble the normal phenotype with respect to eye color, the question arises as to whether uricase activity also regresses towards the wild type. Maternally affected male and female adults had high uricase activity which resembled that of $m a-l$ and not Ore-R (Table IV).

\section{Catalase Activity}

Both catalase and uricase appear to be associated with the same organelle, the microbody, in both vertebrates and invertebrates (Hruban and Rechcigl, 1969; Locke and McMahon, 1971). Catalase and uricase activity might be coordinately controlled. However, there was no significant difference in the

Table IV. Test for Maternal Effect in 1-Day-Old ma-l Female and Male Adults

\begin{tabular}{|c|c|c|c|c|}
\hline $\begin{array}{l}\text { Maternal } \\
\text { genotype }\end{array}$ & $\begin{array}{c}\text { Genotype of } \\
\text { progeny }\end{array}$ & Sex & $\begin{array}{l}\text { Age } \\
\text { (hr) }\end{array}$ & $\begin{array}{l}\text { Uricase activity } \\
\text { of progeny }{ }^{b}\end{array}$ \\
\hline $\mathrm{M} 5 / m a-l^{a}$ & $m a-l / m a-l$ & $\mathrm{~F}$ & 28 & $116.8+8.2(5)$ \\
\hline $\mathrm{M} 5 / \mathrm{ma}-\mathrm{l}$ & $m a-l^{\prime}$ & M & 28 & $107.0 \pm 15.8(5)$ \\
\hline$m a-l / m a-l$ & $m a-l / m a-l$ & $\mathrm{~F}$ & 24 & $83.8 \pm 3.7(5)^{\circ}$ \\
\hline$m a-l / m a-l$ & $m a-l l$ & $\mathbf{M}$ & 24 & $68.9 \pm 7.4(7)^{\circ}$ \\
\hline Ore- $R$ & Ore- $R$ & $F$ & 24 & $8.5 \pm 2.9(9)^{\circ}$ \\
\hline Ore- $R$ & Ore- $R$ & $\mathbf{M}$ & 24 & $2.4 \pm 0.9(7)^{c}$ \\
\hline
\end{tabular}

${ }^{a}$ The M5 stock has the following composition: $\operatorname{In}(1) \mathrm{Sc}^{\mathrm{S}}{ }^{1} \mathrm{Sc}^{8 \mathrm{R}}+\mathrm{s}$, $\mathrm{Sc}^{\mathrm{S1}} \mathrm{Sc}^{8} \mathrm{~W}^{\mathrm{a} B}$.

${ }^{b}$ Mean values are followed by the standard deviations and the number of independent observations in parentheses.

c These values are taken from Fig. 1 and are presented for comparison. 
catalase activity in whole homogenates or isolated Malpighian tubules of 48-hr-old $m a-l$ as compared to Ore- $R$.

\section{DISCUSSION}

If uricase activity in Drosophila were induced by uric acid, there would be no or little uricase activity in $r y^{2}$ and $m a-l$, since these two mutants have no detectable uric acid (Mitchell et al., 1959; Morita, 1958). Both $m a-l$ and $r y^{2}$ had high uricase activity following emergence, indicating that uric acid is not an inducer of uricase in Drosophila. The high uricase activity in ma-l and $r y^{2}$ (Fig. 1) may be due to a metabolite which accumulates in the pupa of ma-l and $r y^{2}$ and is only capable of activating or inducing uricase upon emergence of the adult. This molecule might be xanthine, hypoxanthine, one of their immediate precursors, or possibly one of the pteridines which accumulate in $r y^{2}$ and $m a-l$ but not in Ore-R (Mitchell et al., 1959; Morita, 1958; Hadorn, 1958; Rizki and Rizki, 1962; Hubby and Forrest, 1960; Forrest et al., 1961).

The results of the starvation experiment were consistent with the hypothesis that an inducer or activator of uricase activity is stored in the pupa. No factor in the food was necessary for the rapid increase in uricase activity in $m a-l$, but standard food was necessary for the slow increase in activity in Ore- $R$ females (Table III). Auf der Maur (1961) reported that the increase in uricase activity between the fourth and fifteenth day of adult life in Ore- $R$ and white, a sex-linked mutant, was dependent on a metabolite found in the standard food but not in food containing only sugars.

Since $r y^{2}$ and $m a-l$ from homozygous $r y^{2}$ and ma-l parents, respectively, are also deficient in red pigment, the high or low uricase activity may be correlated with the amount of eye pigmentation. However, maternally affected $m a-l$ males and females have a wild-type complement of eye pigmentation and show the high uricase phenotype. Maternally affected ma-l adults have only 2 to $5 \%$ of the wild-type amount of xanthine dehydrogenase activity at the time of emergence (interpolated from Fig. 3 of Glassman and McLean, 1962). A mutant, white, with no eye pigmentation has only slightly greater uricase activity than Ore- $R$ (Friedman, 1971; Auf der Maur, 1961). Therefore, the high uricase phenotype appears to be strongly correlated with low xanthine dehydrogenase activity and not eye pigmentation.

Finally, are the changes in uricase activity during development of Drosophila a reflection of regulation by inhibitors and activators of a latent pupal uricase and/or the number of enzyme molecules? No definitive evidence for activation or inhibition was obtained. First, the kinetics of uricase activity from $r y^{2}$ and $m a-l$ were essentially identical to that of the wild type. Second, 
homogenates having high uricase activity showed no influence on the uricase activity from homogenates having low or no activity. Third, hypoxanthine, xanthine, and 2-amino-4-hydroxypteridine, which $m a-l$ and $r y^{2}$ accumulate, were inhibitors of uricase in vitro. Isoxanthopterin, absent from $r y^{2}$ and $m a-l$, also inhibited uricase activity and might therefore be an explanation for the reduced levels of uricase activity in Ore- $R$ as compared to ma-l and $r y^{2}$.

Thus uric acid cannot be considered the inducer of uricase activity in Drosophila, since the mutants $r y^{2}$ and $m a-l$ in the absence of uric acid have uricase activity higher than the wild type does. Uricase activity in Drosophila and perhaps in other higher organisms is regulated differently than in some microorganisms in which uric acid is the inducer of uricase. It is possible that one or more of the purine precursors of uric acid or a pteridine which accumulates in the pupa of $r y^{2}$ and ma-l influences uricase activity in $D$. melanogaster.

\section{ACKNOWLEDGMENTS}

I am indebted to Dr. T. M. Rizki, Dr. M. Foster, Dr. L. Nooden, Dr. D. Baic, and Penelope Friedman.

\section{REFERENCES}

Auf der Maur, P. (1961). Experimentell Untersuchungen uber den harnsaure Stoffewechsel bei verschudenen Genotypen von Drosophila melanogaster, $Z$. Vererbungsl. 92:42.

Barrett, D. (1964). Similar accumulation and distribution patterns of two purine oxidizing enzymes in Rana catesbeiana development. Develop. Biol. 10:289.

Baudhuin, P., Beaufay, H., Rahman-Li, Y., Sellinger, O. Z., Wattiaux, R., Jacques, P., and DeDuve, C. (1964). Intracellular distribution of monoamine oxidase, aspartate aminotransferase, $d$-amino acid oxidase and catalase in rat liver. Biochem. J. 92:179.

Brown, A. W. A. (1938). The nitrogen metabolism of an insect (Lucilia sericata). I. Uric acid, allantoin and uricase. Biochem. J. 32:895.

Collins, J. F., and Glassman, E. (1969). A third locus (lpo) affecting pyridoxal oxidase in Drosophila melanogaster. Genetics 61:833.

Courtright, J. B. (1967). Polygenic control of aldehyde oxidase in Drosophila. Genetics $57: 53$.

Forrest, H. S., Hanly, E. W., and Lagowski, J. M. (1961). Biochemical differences between the mutants rosy-2 and maroon-like of Drosophila melanogaster. Genetics 46:1455.

Friedman, T. B. (1971). A study of the effects of mutations at the white, maroon-like and rosy loci on the pattern of uricase activity during development of Drosophila. Doctoral thesis, University of Michigan.

Glassman, E. (1965). Genetic regulation of xanthine dehydrogenase in Drosophila melanogaster. Fed. Proc. 24:1243.

Glassman, E., and McLean, J. (1962). Maternal effect of $m a-l^{+}$on xanthine dehydrogenase of Drosophila melanogaster: II. Xanthine dehydrogenase during development. Proc. Natl. Acad. Sci. 48:1712.

Glassman, E., and Mitchell, H. K. (1959a). Mutants of Drosophila melanogaster deficient in xanthine dehydrogenase. Genetics 44:153.

Glassman, E., and Mitchell, H. K. (1959b). Maternal effect of $m a-l^{+}$on xanthine dehydrogenase of Drosophila melanogaster. Genetics 44:547. 
Glassman, E., Shinoda, T., Duke, E. J., and Collins, J. F. (1968). Multiple molecular forms of xanthine dehydrogenase and related enzymes. Ann. N. Y. Acad. Sci. 151:263.

Hadorn, E. (1958). Contribution to the physiological and biochemical genetics of pteridines and pigments in insects. In $X$ International Congress of Genetics, University of Toronto Press, Toronto, pp. 337-354.

Hruban, Z., and Rechcigl, M. (1969). Microbodies and Related Particles: Morphology, Biochemistry and Physiology, Academic Press, New York.

Hubby, J. L., and Forrest, H. S. (1960). Studies on the mutant maroon-like in Drosophila melanogaster. Genetics $45: 211$.

Kalckar, H. M. (1947). Differential spectophotometry of purine compounds by means of specific enzymes: I. Determination of hydroxypurine compounds. J. Biol. Chem. 167: 429.

Locke, M., and McMahon, J. J. (1971). The origin and fate of microbodies in the fat body of an insect. J. Cell Biol. 48:61.

Lowry, O. H., Rosebrough, N. J., Farr, A. L., and Randall, R. J. (1951). Protein measurements with the Folin phenol reagent. J. Biol. Chem. 193:265.

Mitchell, H. K., Glassman, E., and Hadorn, E. (1959). Hypoxanthine in rosy and maroonlike mutants of Drosophila melanogaster. Science 129:268.

Morita, R. (1958). Purine catabolism in Drosophila melanogaster. Science 128:1135.

Nelson, M. (1964). Some properties of uricase from the housefly, Musca domestica. Comp. Biochem. Physiol. 12:37.

Praetorius, E. (1948). The enzymatic conversion of uric acid: Spectrophotometric analysis. Biochim. Biophys. Acta 2:602.

Razet, P. M. (1953). Recherches sur la localisation des enzyme uricolytiques chez les insectes. Compt. Rend. Acad. Sci. Paris 236:1304.

Rizki, T. M., and Rizki, R. M. (1962). Cytodifferentiation in the rosy mutant of Drosophila melanogaster. J. Cell Biol. 12:149.

Scazzocchio, D., and Darlington, A. J. (1968). The induction and repression of the enzymes of purine breakdown in Aspergillus nidulans. Biochim. Biophys. Acta 166:557.

Tuskuda, H., Mochizuki, Y., and Konishi, T. (1968). Morphogenesis and development of microbodies of hepatocytes of rats during pre- and post-natal growth. $J$. Cell Biol. 37:231.

Watanabe, Y., and Fukumoto, J. (1970). Studies on the formation of uricase by Streptomyces. II. The induced formation of uricase by resting cells. Agr. Biol. Chem. 34:1625.

Yen, T. T. T., and Glassman, E. (1965). Electrophoretic variants of xanthine dehydrogenase in Drosophila melanogaster. Genetics 52:977. 